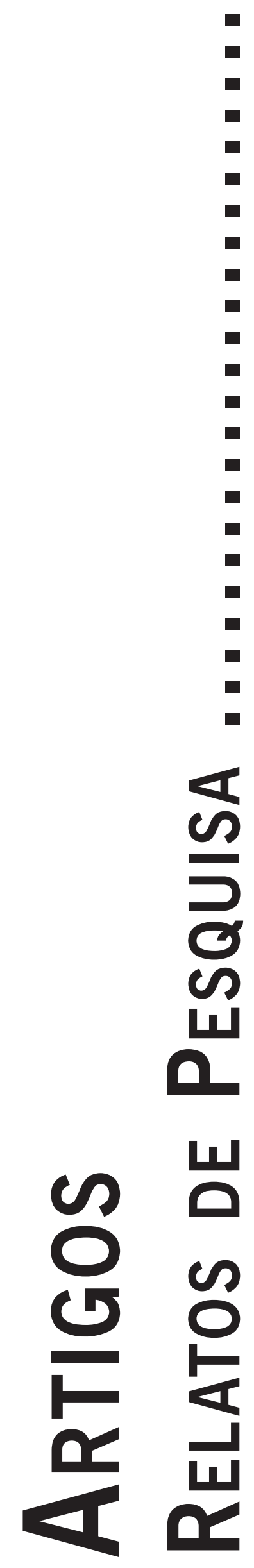




\title{
GESTÃO ORGANIZACIONAL CENTRADA NO GRUPO: RELATO DE EXPERIÊNCIA
}

\author{
Group-Centered Organizational Management: Experience Report \\ Gestión Organizacional Centrada en el Grupo: Informe de Experiéncia
}

ANita BaCELlaR

Joana Simielli Xavier Rocha

MAIRA DE SOUZA FLÔR

\begin{abstract}
Resumo: O presente artigo trata-se de um relato de experiência que apresenta os efeitos dos postulados da Abordagem Centrada na Pessoa em uma Organização de psicologia clínica, chamada Espaço Viver Psicologia, situada em Florianópolis. Tem como objetivo apresentar as organizações de trabalho numa perspectiva da Abordagem Centrada na Pessoa e verificar o processo de evolução das relações pessoais e de trabalho em uma organização centrada no grupo. Para tal, realizou-se uma pesquisa bibliográfica e versões de sentido das pessoas que trabalham em uma organização com modelo administrativo centrado no grupo. Ao final, foi possível reconhecer que a contínua abertura à experiência, a consideração positiva incondicional, a compreensão empática e a autenticidade promovem o desenvolvimento das potencialidades individuais em um contexto de crescimento grupal e organizacional.
\end{abstract}

Palavras-chave: Organizações; Abordagem centrada na pessoa; Grupos.

Abstract: This paper is an experience report that presents the effects of the postulates from the Person Centered Approach in an Organization of clinical psychology, called Espaço Viver Psychology, located in Florianópolis. The objectives of the study are, introduce work organizations from the perspective of the Person Centered Approach and verify the process of development in personal and work relationships. Bibliographic research and sense's version were taken of people working in an organization with an administrative model centered group. In the end, it was possible to recognize that the continuous opening to experience, unconditional positive regard, empathic understanding and authenticity promote the development of individual potential in the context of group and organizational growth.

Keywords: Organization; Person-centered approach; Groups.

Resumen: El presente artículo es un relato de experiencia que presenta los efectos de los postulados del Enfoque Centrado en la Persona en una Organización de la psicología clínica, llamada Espaço Viver Psicologia, situado en Florianópolis. Tiene como objetivo presentar las organizaciones que trabajan con una vista del Enfoque Centrado en la Persona y comprobar el proceso de la evolución de las relaciones personales y el trabajo en una organización centrada en el grupo. Para eso se realizó una búsqueda bibliográfica y las versiones de significado de las personas que trabajan en una organización con un enfoque administrativo centrado en el grupo. Al final, fue posible reconocer que la continua abertura a la experiencia, la consideración positiva incondicional, la comprensión empática y la autenticidad promocionan el desarrollo del potencial individual en un contexto de crescimiento del grupo y de la organización.

Palabras clave: Organizaciones; Enfoque centrado en la persona; Grupos.

\section{Introdução}

Vivemos em um mundo no qual, através dos recursos da tecnologia, recebemos múltiplas estimulações em uma velocidade e força tão intensa, que exige de todos nós um grande exercício de adaptação. O mundo se desenvolve a passos largos e, com ele, as organizações de trabalho e as relações interpessoais. Trabalhar neste contexto, de forma saudável e embarcar nesta fluidez de desenvolvimento, requer criatividade e flexibilidade nas relações. A Psicologia, ao longo da sua história, tem se empenhado para produzir conhecimento e recursos que facilitem o desenvolvimento humano e de suas relações em diferen- tes contextos da vida. Como fruto dessa caminhada encontramos teorias psicológicas que apresentam diferentes visões de homem, de mundo e de desenvolvimento humano, gerador de diversas formas de fazer Psicologia.

Greening (1975) e os colaboradores de sua obra, a partir de uma verificação que aglutina e sistematiza as teorias psicológicas, nos ajudam a entender a evolução e as diferenças das propostas elaboradas até então. O Behaviorismo foi considerado como uma das grandes forças da Psicologia. Greening (1975) descreve o Behaviorismo, como uma teoria psicológica que apresentou uma visão do funcionamento humano compatível com os moldes científicos positivistas de sua época. 
Com o desenvolvimento científico do Behaviorismo clássico, surgiu entre os estudiosos, uma insatisfação com o modelo estritamente comportamental e a necessidade de acrescentar na sua visão de homem aspectos que vão além do comportamento manifesto.

Vale realçar que "com o movimento recente em direção à prática baseada em evidências, a Terapia Cognitiva recebeu atenção destacada” (Knapp \& Beck, 2008, p.63). Sua tradição de realizar pesquisas empíricas as aproxima principalmente da comunidade médica, que com sua compreensão orgânica, tende a se identificar com a linguagem comportamental, pela proximidade positivista. Ainda mais recentemente, na última década, a Psicologia Positiva tem utilizado alguns aspectos cognitivos, com a intenção de produzir nas pessoas pensamentos e sentimentos qualitativamente positivos, e assim, criar um foco de atenção nas virtudes humanas.

Sua principal preocupação é ampliar o campo e modificar o foco dos estudos, ou seja, a Psicologia não está restrita apenas a reparar o que está errado ou ruim, mas (re)construir qualidades positivas; ele afirma que o tratamento psicológico e as pesquisas não devem pretender apenas consertar ou descobrir o que está "quebrado" ou não funciona, mas fomentar e nutrir o que existe de melhor nos indivíduos (Paludo \& Koller, 2007, p. 12).

Seus representantes descrevem a Psicologia Positiva como uma abordagem teórica que valoriza o ser humano, o que supostamente a aproximaria da Psicologia Existencial-Humanista. No entanto, o fato de propor atividades que levem a produção de comportamentos positivos e ao afastamento dos comportamentos negativos, a distancia desta perspectiva e a aproxima das Terapias Cognitivas.

Para Greening (1975) e seus colaboradores, temos a Psicanálise como uma segunda grande força da Psicologia. Desenvolvida na Europa, em meio aos fortes valores sociais e religiosos da época, considerou como desviante todas as manifestações humanas que não se enquadrassem nos modelos adotados e construiu uma explicação para o funcionamento humano que produz um clima de desconfiança e pessimismo em relação a natureza humana e a sua possibilidade de transformação.

A sociedade baseava-se (disse Freud) na renúncia dos instintos, através do mecanismo de repressão; mas os instintos não se rendiam sem luta. De fato, nunca se renderam; não podiam ser vencidos, apenas temporariamente bloqueados. (...) Tanto para a pessoa individual como para a cultura não existia solução permanente nem desfecho feliz; apenas havia compromissos, expedientes, ajustamentos operacionais (Matson, 1975, p. 73).
Apesar de haver uma forte corrente tradicionalista na Psicanálise, outras proposições teóricas psicanalíticas foram desenvolvidas. No entanto, a base de todas é a luta entre a pulsão e a repressão, diante da qual a pessoa é refém.

Em síntese, percebe-se nessas duas raízes, por um lado, o desenvolvimento de teorias e técnicas interventivas que buscam motivar e direcionar o comportamento humano para padrões de produtividade e felicidade. Enquanto, por outro lado, o desenvolvimento de intervenções psicológicas que buscam explicar e interpretar as pulsões humanas. Se, por um lado, temos sugestões de direções a serem seguidas para que as pessoas se tornem mais felizes, por outro lado, temos explicações sobre emoções e atitudes do ser humano. Até aqui, estamos diante de teorias psicológicas que tem como proposta transformar as pessoas no que elas consideram mais adequado para a vida social de sua época. Ou seja, as teorias psicológicas mencionadas propõem que as pessoas sejam controladas em suas pulsões ou em seus comportamentos.

O referencial teórico da terceira força, denominada por Grenning (1975), de Psicologia ExistencialHumanista, em especial a Abordagem Centrada na Pessoa (ACP), desenvolvida pelo psicólogo norte-americano Carl Ransom Rogers, desde 1940, têm sua genêse na compreensão das relações humanas como o grande gerador do desenvolvimento humano. Através da Psicologia Existencial-Humanista foi possível resgatar a importância das potencialidades humanas e a ausência de determinação humana. Nem as forças internas (pulsões) e nem as forças externas (meio ambiente) têm poder para determinar pensamentos, sentimentos e atitudes de uma pessoa. E sabem por quê? Por que além das influências internas e/ou externas, existe a forma como cada um percebe a realidade e o modo como escolhe reagir a realidade percebida. Nesse contexto, mantém-se o respeito pelo livre arbítrio humano e a proposta de ampliar a compreensão das pessoas sobre sua responsabilidade diante de suas escolhas na vida. Não há direcionamentos, interpretações sobre o funcionamento das pessoas e sim relações comprometidas com a compreensão em favor do seu autodesenvolvimento.

O olhar diretivo, explicativo e determinista presente nas perspectivas teóricas apresentadas anteriormente, limita o entendimento do ato compreensivo proposto pela terceira força, fazendo com que a comunidade científica a reconheça, na maioria das vezes, como uma teoria ingênua e simplista. Uma das respostas possíveis para esta dificuldade parece estar no fato das teorias Behaviorista e Psicanalítica, elegerem explicar as vivências humanas, enquanto a Abordagem Centrada na Pessoa se propôs a compreender o jeito de ser da pessoa na vida.

Estamos diante de uma proposta que para ser compreendida, em sua profundidade e complexidade, exige a ruptura com a lógica do paradigma tradicional e o exercí- 
cio de uma abertura à experiência organísmica, ou seja, uma disponibilidade para tornar consciente tudo o que se passa com o meu organismo em qualquer momento da vida. Uma abertura que garanta a exploração constante da experiência, permitindo uma ampliação e/ou reformulação da experiência.

Embutido na simplicidade das palavras de Rogers existe uma complexidade que, ainda hoje, promove reflexões e desdobramentos que contribuem com a ampliação da compreensão das relações humanas no contexto socioeconômico e cultural do século XXI. Foi por considerar essa característica que Carl Rogers e estudiosos centrados na pessoa se abriram e ainda se abrem à experiência, com o objetivo de contribuir, cada vez mais, com o desenvolvimento humano nos diferentes contextos.

Dentre os diferentes contextos da vida humana: família, lazer, trabalho, entre outros, há uma percepção comum na atualidade de que o trabalho ocupa boa parte das nossas vidas. Seja em termos de tempo cronológico, como herança da Revolução Industrial, ou em termos de intensidade de dedicação, o trabalho está no centro de nossas vidas. A partir do reconhecimento deste contexto, uma das propostas da Psicologia na atualidade é ampliar as reflexões sobre as relações das pessoas com o trabalho e sobre o desenvolvimento das organizações de trabalho em si. Nesta perspectiva, a ACP pode contribuir com a proposta de um novo jeito de estar nas organizações.

Quando pensamos em uma organização que segue os pressupostos da Abordagem Centrada na Pessoa há um olhar que vai além da estruturação concreta das organizações, que flexibiliza as compreensões e as escolhas de trabalho a partir das relações. Estamos falando de um lugar que considera que os sentimentos podem ser expressos livremente, destituídos de julgamento de valor ou interpretações.Viver experiências com pessoas que estejam abertas para viver o fluxo das relações e apresentar-se genuinamente em todas as circunstâncias, permite que as dúvidas e/ou desentendimentos possam ser reconsiderados e os entraves possam ser desfeitos, facilitando a comunicação experiencial.

É com a expectativa de contribuir com a contínua abertura à experiência que apresentamos o presente artigo, classificado como um relato de experiência que se propõe a apresentar os resultados alcançados nas relações de trabalho a partir da aplicação dos postulados da Abordagem Centrada na Pessoa no dia-a-dia de uma organização de trabalho que se dedica a prática da Psicologia Clínica.

\section{Compreendendo a experiência: uma proposta me- todológica}

O Espaço Viver Psicologia é uma clínica, fundada em 2008, que se caracteriza por oferecer diferentes serviços de atendimento psicológico, com base na Abordagem
Centrada na Pessoa. Além da clínica psicológica, a instituição conta com um centro de formação que oferece cursos de aprimoramento e especialização para a comunidade em geral, garantindo o acompanhamento constante de seus profissionais e a permanente qualidade do serviço. Nestes seis anos de atividade, o Espaço Viver Psicologia consolidou a missão de facilitar os processos de superação das necessidades emocionais e por esse trabalho tem sido reconhecido como um centro de referência, tanto pelas pessoas que usufruem do serviço, como pelas instituições de saúde pública e saúde privada, que somos credenciados como prestadores de serviço.

Sustentadas pela concepção de que os postulados da Abordagem Centrada na Pessoa transcendem a relação psicoterapêutica, ultrapassam a aplicação de uma técnica, se caracterizam como um jeito de ser e estão presentes em todas as relações humanas, nos propomos a estar nas nossas relações de trabalho (entre psicólogos) dispostos a exercitar o jeito de ser centrado na pessoa. Desta forma, cabe salientar que nos dedicaremos neste artigo aos efeitos da aplicação dos postulados desta Abordagem nas relações destes profissionais.

Para atingir esse objetivo, o artigo pretende caracterizar as organizações na atualidade, apresentar as organizações de trabalho numa perspectiva da Abordagem Centrada na Pessoa e verificar o processo de evolução das relações interpessoais em uma organização centrada no grupo. Utilizamos como recurso metodológico uma pesquisa bibliográfica articulada a versões de sentido das pessoas que trabalham em uma organização com modelo administrativo centrado no grupo. Entende-se versão de sentido como um instrumento fenomenológico caracterizado como “(...) um relato livre, que não tem a pretensão de ser um registro objetivo do que aconteceu, mas sim de ser uma reação viva a isso, escrita ou falada imediatamente após o ocorrido, e como uma palavra primeira" (Amatuzzi, 1996, p.12).

Para tal, foi solicitado aos participantes da pesquisa que escrevessem um texto livre, sem preocupação com formatação ou escrita formal, sobre como percebem a experiência de trabalho no Espaço Viver Psicologia e qual o significado dessa experiência em suas vidas dentro ou fora da organização. Após convite das autoras, cinco profissionais da organização apresentaram suas versões de sentido, três profissionais não participaram por serem as autoras desse artigo e uma pessoa escolheu não participar. Ao longo da construção do artigo, buscou-se articular reflexões obtidas pela experiência das autoras, associadas ao estudo bibliográfico e ao resultado da categorização e análise qualitativa das versões de sentido.

Nesse momento, nos cabe ainda realçar que este artigo tem o compromisso de resgatar as contribuições de Rogers e estendê-las ao contexto das relações de trabalho nas organizações. Consideramos que a melhor forma de apresentar a essência das contribuições de Rogers é pro- 
porcionar o acesso as suas próprias palavras. Desta forma, mantivemos, sempre que possível, citações literais de sua obra, mescladas com nossas reflexões e com as versões de sentido já citadas.

\section{As organizações de trabalho na atualidade}

As Organizações representam a possibilidade das pessoas realizarem atividades complexas demais para serem executadas individualmente. Sendo assim, caracterizam-se como um local em que as pessoas se reúnem para trabalhar e o produto promove o desenvolvimento das potencialidades de cada membro do grupo e da organização como um todo. Nessa perspectiva, as organizações exercem uma função que ultrapassa as questões de estrutura e de processo, já que contempla uma grande rede de relações humanas, interpessoais e sociais. Cabe também salientar que vivemos um complexo sistema das organizações no contexto atual.

O termo pós-modernidade surge para designar a cultura produzida numa sociedade cuja evolução tecnológica se põe além da produção industrial de bens materiais. Se a economia capitalista baseada na industrialização é o cenário da cultura da modernidade, a superação dela e de sua base técnica daria vazão ao aparecimento de uma cultura pós-moderna, pois que esse quadro representaria o esgotamento da própria modernidade (Giddens, 1991, p. 153).

Essa nova realidade sociocultural, econômica e tecnológica lança as organizações no domínio da informática, gerador de um produto informacional e levará a uma reconceituação do significado de trabalho e de organização. Nesse contexto, a realidade do mercado de trabalho no mundo pós-moderno exige saídas criativas e condizentes com a realidade flutuante das experiências relacionais do mundo ocidental atual. Na prática, ainda se percebe exigências características do período Moderno, no entanto, essas duas exigências apresentam-se incompatíveis, pois, o estabelecimento de um clima que prioriza a avaliação por produtividade, limita o espaço para a produção de escolhas e a percepção de pertencer ao grupo. Essas características por si só dificultam o potencial criativo e a harmonia no ambiente de trabalho, restringem as possibilidades de crescimento pessoal e organizacional, e tendem à estagnação (Siqueira \& Spers, 2001).

A organização é geralmente vivenciada como um processo de controle que flui de cima para baixo. Isto pode ocorrer por meio de ordens e regulamentos, ou de recompensas concedidas seletivamente, tais como promoções e aumento de salário. Recentemente, muitas das maiores empresas (...) têm tentado descentralizar a autoridade, responsabilidade e iniciativa por toda organização, especialmente em níveis gerenciais (...) efeitos construtivos foram observados em certas indústrias (Rogers, 1977/2001, p. 103).

Nesse contexto, se as organizações existem para que um grupo de pessoas seja capaz de gerenciar aspectos que uma pessoa sozinha não seria capaz de fazer, então a comunicação se torna o principal veículo para a consolidação das atividades em grupo e para o alcance dos objetivos a serem atingidos. A comunicação interpessoal nas organizações costuma ser parcialmente clara e direcionada para a realização concreta das atividades de trabalho, no entanto, a comunicação dos sentimentos e a apresentação de si para o grupo fica inviabilizada pelas características das relações humanas atuais.

O formato das relações na atualidade, onde cada um busca sua própria realização sem considerar as pessoas com quem se relaciona, fez com que a comunicação passasse a ser um complicador nas relações de trabalho, visto que se relacionar com as diferenças em uma realidade capitalista, torna-se cada dia mais difícil. Conforme Marchiori (2009, p. 8): “A comunicação como constitutiva requer o entendimento de que inúmeras realidades existem dentro de um mesmo espaço e fazem sentido para o grupo que participa daquela realidade (...) isto significa aprender a viver e conviver na diversidade".

Considerando essas reflexões, pode ser produtivo para as organizações de trabalho na atualidade construir um clima no qual a diversidade possa existir nas relações interpessoais, no qual exista abertura para a resolução de conflitos gerados pelas eventuais dificuldades na comunicação. Nessa perspectiva, compreender uma organização com essas características, a luz da Abordagem Centrada na Pessoa pode trazer importantes contribuições para o seu desenvolvimento.

\section{As organizações de trabalho em uma perspectiva centrada no grupo}

Rogers propunha a teoria do funcionamento ótimo da personalidade como uma direção natural para onde o organismo se direciona, numa perspectiva de buscar o ápice do desenvolvimento da sua personalidade. Segundo ele, o avanço nessa direção natural se dá à medida que as pessoas são guiadas pela percepção dos seus sentimentos, provocados pela realidade que as cerca, ou seja, pelas sensações organísmicas que o ambiente e as relações interpessoais lhe despertam. "Quanto mais uma pessoa implicar-se em suas experiências organísmicas, maior será seu trabalho de potencializar os recursos para resolver os seus problemas e se atualizar, de acordo com o que há de mais genuíno em seu organismo" (Branco, 2008, p.75).

À medida que as pessoas se aproximam desse referencial interno para embasar suas atitudes, sua persona- 
lidade desenvolve características que podem ser descritas em três grandes aspectos indivisíveis e inseparáveis. Seriam eles: a atitude de abertura à experiência, o modo de funcionamento existencial e o organismo digno de confiança (Rogers \& Kinget, 1959/1977).

Nessa perspectiva, segundo Rogers, a grande função das pessoas enquanto membros de um grupo seria a crença na importância de buscarmos ser nós mesmos para, em seguida, desenvolver a capacidade de:

Estar plenamente abertos - primeiro um em relação ao outro e depois em relação ao grupo todo; estar preparados para explorar áreas novas e desconhecidas de nossas próprias vidas; aceitar verdadeiramente nossas próprias diferenças e estar abertos para as novas aprendizagens, possibilitadas pelas recentes viagens ao nosso interior, estimuladas pelas experiências vividas na equipe e no grupo (Rogers, 1980/1983, p. 56).

Enquanto a abertura à experiência provoca esta sensação de unicidade e segurança no grupo, as relações empresariais existentes nos dias atuais provocam sensação de insegurança e instabilidade. As falhas na comunicação levam a percepções incompletas da realidade acompanhadas de julgamentos parciais que desenvolvem insatisfações e conflitos. A atitude de abertura à experiência, em contraponto, remonta à capacidade de percepção plena e integral do que a experiência provoca no organismo, sem distorções ou negações.

A pessoa que busca se aproximar do funcionamento pleno, desenvolve um acordo entre a imagem de si e a experiência organísmica. Desta forma, cada vez menos elementos da realidade causam ameaça à sua imagem, ao ponto desses elementos precisarem ser distorcidos ou negados. $\mathrm{O}$ fato dos dados da experiência, em sua maioria, serem acessados pela consciência, minimiza a possibilidade de ansiedade ou angústia, fruto da incompreensão da experiência.

Assim sendo, quanto maior o predomínio desse jeito de ser, menor vontade de julgar ou manipular estará presente nas relações. Quanto maior a capacidade de aceitar as pessoas integralmente, com suas qualidades e limitações, maior a ampliação do potencial criativo e da capacidade de transformar suas atitudes (Rogers, 1980/1983).

Uma pessoa aberta à experiência vive um funcionamento existencial, uma vez que cada experiência se torna única, sem a criação de expectativas e comparações com as experiências passadas. Além disso, a pessoa que vive o funcionamento existencial caracteriza-se por uma fluidez expressa em viver a vida como um processo e não como um estado. Eis, segundo Rogers, as características que marcam o grande diferencial da organização centrada no grupo:

A vida, a vitalidade e a crescente capacidade do Centro estavam intimamente ligadas à sua falta de rigidez, à sua capacidade continuamente surpreendente de mudar sua mentalidade coletiva e de utilizar um novo modo de funcionamento (Rogers, 1977/2001, p. 107).

Por fim, outra característica da pessoa que busca o funcionamento ótimo seria reconhecer o seu organismo como digno de confiança, um guia para as atitudes a serem adotadas em todas as situações vividas. Estes três aspectos, além de serem, inseparáveis e concomitantes, como já foi dito, são dinâmicos, ou seja, um funcionamento de personalidade inacabado, que não para de se aprimorar e que apresenta recursos internos adaptativos a qualquer realidade que se interponha.

A personalidade que funciona plenamente é uma personalidade em contínuo estado de fluxo, uma personalidade constantemente mutável, cujos comportamentos específicos não se prestam à predição. A única predição que poderia ser feita ao indivíduo sobre seu comportamento é que ele manifestará em qualquer ocasião um grau perfeito de adaptação criativa e que estará comprometido num processo contínuo de atualização (Rogers \& Kinget, 1959/1977, p. 212).

Pessoas que se propõem a guiar suas relações a partir desse referencial desenvolvem uma capacidade de comunicação assertiva e resolutiva. Uma comunicação que apresenta a raiz dos desconfortos e dos conflitos e, a partir disso, encontra recursos de superação das dificuldades. Eis a comunicação que promove o crescimento do grupo e da organização como um todo. Rogers se refere a isso nas seguintes reflexões sobre o trabalho em uma organização centrada no grupo:

Descobri a enorme importância dos sentimentos pessoais em questões administrativas. Frequentemente, a equipe passava horas (ou pelo menos assim o parecia) discutindo um problema trivial (...). A partir do momento em que os sentimentos eram trazidos à tona, o problema que anteriormente parecia ser tão importante esvaziava-se. Por outro lado, quando a equipe se comunicava abertamente, questões sérias como fixação de orçamento para o próximo ano, a eleição de um coordenador, adoção de uma importante política, podiam ser decididas em questão de minutos (Rogers, 1977/2001, p.108).

Embora este seja um funcionamento ótimo e não real, é possível vislumbrar uma aproximação deste funcionamento, principalmente quando uma pessoa está inserida em um grupo que pretenda conscientemente empreender esforços em conjunto para desenvolver tais características. Podemos pensar, então, na teoria de funcionamento ótimo da personalidade aplicada ao grupo. Neste caso, abertura a experiência, fluidez e confiança no potencial do grupo tornam-se uma possi- 
bilidade. Desta forma, os esforços de cada um na busca da experienciação organísmica atuam como um catalizador na busca do outro, promovendo um crescimento equânime e auto regulador no grupo. Assim como um organismo tem "um fluxo subjacente de movimento em direção à realização construtiva das possibilidades que lhe são inerentes” (Rogers, 1980/1983, p.40), processo denominado por Rogers de Tendência Atualizante, o grupo e a vida no geral também se autorregulam em uma Tendência Formativa que:

Trata-se de uma tendência evolutiva para uma maior ordem, uma maior complexidade, uma maior inter-relação (...) que não se encontra apenas nos sistemas vivos, mas faz parte de uma poderosa tendência formativa do nosso universo, evidente em todos os seus níveis (Rogers, 1980/1983, p. 50).

Se um grupo de trabalho se propõe a viver em constante estado de acordo interno, buscando saídas criativas e adaptativas diante do que a realidade apresenta, logo, podemos naturalmente considerar que esta organização também tende a realizar suas potencialidades, regulando-se às necessidades do mercado e expandindo-se de acordo com suas possibilidades organizacionais. Podemos relacionar este funcionamento organizacional ao funcionamento pleno da personalidade. Estas seriam as características de uma organização centrada na pessoa, que promove tanto o desenvolvimento pessoal das pessoas que fazem parte da organização, quanto o desenvolvimento organizacional.

Referindo-se a isso, Rogers afirma:

Espero ter deixado claro que é perfeitamente possível ter uma organização centrada-na-pessoa, na qual as bases de poder e controle são sentidas, pelo indivíduo, como se estivesse dentro dele próprio. Está solidamente comprovado que, em tal organização, os indivíduos podem e realmente trabalham juntos, de modo responsável, para estabelecer objetivos, para determinar as orientações a seguir, para tratar de detalhes administrativos, para utilizar diferentes modalidades organizacionais e para lidar com as crises que inevitavelmente ocorrem. O grupo está mais capacitado para tomar decisões sábias do que uma única pessoa, pois ele apela para as potencialidades de liderança de todos (Rogers, 2001, p.118).

Recentemente, algumas experiências de consultorias de promoção do desenvolvimento organizacional demonstram que, compreensões ampliadas das relações humanas, como a compreensão da ACP, quando transformadas em atitudes, podem promover transformações que beneficiam os vários níveis organizacionais. Considera-se como uma das principais contribuições destes estudos a percepção de que
(...) não se tratava, por tanto, de exigir dos indivíduos capacidades ou conteúdos que eles não dispõem eventualmente, enfraquecendo ou vulnerabilizando, ainda mais, o indivíduo concreto -, mas identificar as zonas de excelência e potencialidade individual, articuladas com as capacidades dos demais, para contribuir com eficiência a respeito do que de melhor podem oferecer (Simeão \& Sousa, 2009, p. 79).

\section{Da pessoa ao grupo, do limite à potência: uma relação experiencial}

Consideração positiva incondicional, compreensão empática, autenticidade e liberdade experiencial, são conceitos que estão presentes em toda a obra de Rogers, não apenas no que diz respeito à relação terapêutica, mas à todas as relações que tem como objetivo promover o desenvolvimento das potencialidades humanas. Quando o assunto é relações de trabalho em uma organização centrada no grupo esses princípios se transformam em um jeito de ser, de viver e de se relacionar.

As relações de trabalho centradas no grupo vão se desenvolvendo a partir da crença de que a "nossa maior tarefa é sermos nós mesmos” (Rogers, 1980/1983, p. 56). Na convivência os integrantes do grupo vão, gradativamente, provocando reflexões e percepções em seus integrantes que, por sua vez, precisam, necessariamente, se disponibilizar a refletir sobre si mesmos a partir das experiências relacionais. Assim, as relações têm como base uma comunicação clara e pautada na experiência organísmica. Há um constante olhar para as próprias sensações e sentimentos experienciados. Essas sensações e sentimentos tornam-se conscientes e são apresentadas ao grupo sempre que necessário para garantir o desenvolvimento e a concretização das produções organizacionais. Como essas percepções e comunicações são necessariamente genuínas provocam sensações e sentimentos nos outros, geradores do desenvolvimento das potencialidades pessoais e do grupo.

Em nossa experiência, durante todo o dia de trabalho todos os integrantes da equipe do Espaço Viver Psicologia, mesmo em diferentes momentos do desenvolvimento pessoal e profissional, sentem-se responsáveis por estarem atentos ao seu crescimento. E as funções de coordenação e de gerência são desempenhadas por pessoas reconhecidas pelo grupo, naquele período, com possibilidades de realizar tais funções. A partir da prática profissional e da relação grupal, desenvolve-se um comprometimento de todos em facilitar o desenvolvimento dos demais integrantes do quadro de psicólogos, assim como da organização como um todo, através da postura de consideração positiva incondicional, compreensão empática e autenticidade. O comprometimento com o desenvolvimento grupal pode ser mais bem compreendido na descrição de genuinidade ou autenticidade, considerada por 
Rogers como uma atitude indispensável quando o assunto é despertar o crescimento no outro.

Devo estar consciente de meus próprios sentimentos, o mais que puder (...) ser genuíno também envolve a disposição para ser e expressar, em minhas palavras e em meu comportamento, os vários sentimentos e atitudes que existem em mim (...) é somente ao apresentar a realidade genuína que está em mim, que a outra pessoa pode procurar pela realidade em si com êxito (Rogers, 1961/1997, pp. 37-38).

O exercício da autenticidade no grupo promove a entrega das pessoas, umas às outras, essa entrega é geradora de um sentimento comum no grupo, um sentimento de unidade, de confiança no potencial do grupo. Essa percepção pode ser ilustrada nos trechos das versões de sentido a seguir:

"todas as pessoas estão conectadas umas às outras, muito atentas ao outro para promover crescimento e muito atentas a si mesmo para estar em crescimento. Juntas conseguimos formar um grupo de fato, que se sente fazendo parte do trabalho, trabalho esse que por gerar crescimento constante e estar sempre girando em torno da autenticidade de cada um, dá orgulho de participar e ser um pedaço disso tudo que se torna um só.” (psicóloga 1)

O exercício da autenticidade, da consequente entrega e sentimento da unidade do grupo é terreno fértil para a ampliação da consideração positiva incondicional de si e do outro. Com esta atitude surge espaço para o reconhecimento das limitações, a possibilidade de buscar um caminho de superação e consequentemente desenvolvimento das potencialidades. Embora ao longo do processo de desenvolvimento haja sentimentos de auto cobrança e de decepção diante das falhas de percepção da realidade, o grupo busca apresentar as falhas, mas manter a consideração pela intenção na pessoa. Para Rogers (1961/1997, p. 38),

(...) quanto mais aceitação e apreço sinto com relação a esse indivíduo, mais estarei criando uma relação que ele poderá utilizar. Por aceitação, quero dizer uma consideração afetuosa por ele enquanto uma pessoa de auto valia incondicional - de valor, independente de sua condição, de seu comportamento ou de seus sentimentos.

O sentimento de ser considerado incondicionalmente também é percebido como facilitador de crescimento pelas integrantes do grupo:

"tive pessoas ao meu lado que me ajudaram a perceber o quanto eu mesma atrapalhava meu processo de aprendizado. Essas pessoas me ajudaram a perceber o movimento que eu fazia e tudo que eu perdia oportunidades, energia, relações - e mesmo assim, me consideraram. Estiveram ao meu lado mesmo quando qualquer outra pessoa escolheria se afastar. (...) Hoje posso dizer que cada vez me aproximo mais da pessoa que eu realmente sou, descobrindo meus limites e minhas potências.” (psicóloga 2)

A liberdade de perceber e compreender sua dinâmica de funcionamento psicológico é um dos benefícios que a experiência de grupo pode trazer. Ao se referir aos efeitos causados e percebidos pelas pessoas após vivências em grupo, Rogers afirma que:

É muito frequente esta sensação de maior verdade e autenticidade. É como se o indivíduo aprendesse a aceitar-se e a ser ele próprio, lançando assim as bases para uma mudança. Está mais perto dos seus próprios sentimentos, que por isso, não são já tão rigidamente organizados e estão mais abertos à mudança (Rogers, 1970/1974, p. 39).

Esse sentimento de maior aceitação de si mesmo é promovido pelas relações nas quais haja atitudes de consideração positiva incondicional e compreensão empática. Esta última, compreendida como uma "capacidade de se imergir no mundo subjetivo do outro e de participar da sua experiência, na extensão em que a comunicação verbal ou não-verbal permite” (Rogers, 1977, p. 104). Atitudes como esta promovem nos membros do grupo o sentimento de acolhida e de compreensão de suas dificuldades.

"Pude enxergar o quanto estava longe de mim, o quanto eu não existia. Fui percebendo que para algumas pessoas parecia ser muito fácil, mas para outras era como se elas sentissem o mesmo que eu. E então fui compartilhando isso com elas, e fui percebendo que quanto mais me entregava para as relações, mais era aceita e mais eu queria viver aquilo.” (psicóloga 3)

Essas reflexões nos levam a pensar o quanto nos formatos tradicionais das organizações na atualidade se faz necessário o desenvolvimento de mediações de conflito. Percebe-se que em uma organização centrada no grupo, as atitudes de consideração positiva incondicional, compreensão empática e autenticidade dissolvem os conflitos que possam existir. As disputas de poder, característica central dos conflitos, se dissipam, pois as relações são horizontais.

Viver relações que contenham essas três atitudes promove no outro um consequente sentimento de liberdade experiencial. Nota-se que ao conviver com pessoas que estão abertas a experiência e atentas ao seu próprio desenvolvimento pessoal, nos tornamos também atentos a nossa experiência íntima em relação a cada aspecto vi- 
venciado em nosso dia a dia. A certeza de que não haverá julgamentos por nossas atitudes ou sentimentos e de que o afeto não está condicionado ao desempenho de nossas atividades, nos permite viver cada dia mais integralmente as experiências no momento presente. Como consequência surge o sentimento de liberdade para explorar sentimentos que, muitas vezes, ficavam escondidos dentro de nós. Somos envolvidos por um sentimento de segurança que nos motiva a ampliar nossa consciência, percepções, sensações e sentimentos, fruto de cada experiência. Poder vivenciar aspectos, que antes eram ocultos ou escondidos, sem medos ou receios, leva ao caminho de crescimento individual.

O indivíduo se sente livre para reconhecer e elaborar suas experiências e sentimentos pessoais como ele o entende. Em outras palavras: supõe que o indivíduo não se sinta obrigado a negar ou a deformar suas opiniões e atitudes íntimas para manter a afeição ou o apreço das pessoas importantes para ele (Rogers \& Kinget, 1959/1977, p. 46).

Não há nada que não possa ser expresso ou sentido, existe espaço para ampliar a percepção em relação a qualquer experiência vivida, sem medos ou receios,

"e estar lá foi dando a certeza de 'eu sou alguém, que tem espaço para ser'. E a partir disso, foi cada vez mais gostoso estar lá e cansativo também, pois pude aprender que viver, às vezes cansa” (psicóloga 1);

"Trabalhar no Espaço Viver significa ter um espaço facilitador e livre para que eu consiga desenvolver minhas habilidades" (psicóloga 2);

"No Espaço Viver me sinto livre para ensaiar reflexões, novos significados, novas atitudes. Me sinto livre principalmente para expressar sentimentos, independente se são considerados positivos ou negativos e assim trabalhá-los” (psicóloga 3).

O sentimento de liberdade para viver a experiência faz ressurgir, dentro de cada um, uma tendência natural ao crescimento. Através dela descobrirão suas potências e habilidades, levando a um desenvolvimento contínuo. Assim, novas atitudes passam a ser ensaiadas, novas saídas são encontradas, uma percepção cada vez mais integral de si e do grupo é desenvolvida. Essa liberdade experiencial promove sentimento de expansão das habilidades reflexivas e se estende às relações. $\mathrm{O}$ contato entre pessoas com propostas de vida semelhantes, exercitando suas reflexões, minimiza distorções, possibilidades de conflito, amplia a coesão do grupo e torna sua relação com a realidade mais clara.

O sentimento da formação gradual do grupo é perceptível a todos, de acordo com Rogers (1970/1974, p.
21), “(...) uma das evoluções mais frequentes é o sentimento de confiança, que começa lentamente a construir-se, e também um sentimento de calor humano e simpatia pelos outros membros do grupo". A construção da confiança foi gradualmente percebida por participantes do grupo:

"Sinto que todos estão nesse mesmo fluxo, cada um no seu processo e isso me deixa mais entusiasmada para ensaiar principalmente me relacionar de uma forma mais congruente, mesmo isso não sendo fácil assim. No Espaço Viver posso ensaiar e aprender a ser a pessoa que desejo ser.” (psicóloga 2);

"Há 3 anos passei a conhecer o que é viver em grupo, desde então me encantei com as relações e esse novo jeito de me relacionar, descobri o quanto crescemos nos relacionando com o outro.” (psicóloga 5).

Percebe-se, portanto, que, quanto mais as pessoas experimentam relações com pessoas que apresentem atitudes facilitadoras, mais se autorizam a experienciar tudo o que sentem e percebem das relações, criando espaço para resignificar ideias, valores e conceitos, tornando-se mais autênticas e realizadas. Esse despertar interfere diretamente nas demais pessoas que fazem parte do grupo, possibilitando a construção de uma organização onde todos possam ser considerados.

"Ainda me sinto menina, reconheço a minha pequenez em que horas sou uma lagarta envolvida por um casulo de medos e fragilidades que precisam amadurecer, horas uma pequena borboleta que encontra espaço e liberdade para bater as suas asas e expor o que sente e acredita" (psicóloga 4).

A transformação de cada um vai afetando suas relações fora do trabalho, assim como a postura organizacional vai mostrando ao mercado que há como crescer financeiramente e estruturalmente garantindo o desenvolvimento das potencialidades das pessoas.

"E comecei a sentir a vontade de viver isso em outras relações, mudar a forma de estar com as pessoas, e foi dando a sensação de que isso já faz parte de mim” (psicóloga 3).

O trabalho desenvolvido ganha destaque, pois todos assumem, juntos, o resultado do trabalho. Deixa de existir um em cada função, para existir um grupo que busca o crescimento de todos. Com isso, os membros do grupo sentem-se livres para criar e explorar aspectos de si mesmos que antes não reconheciam como potentes, levando consequentemente ao crescimento organizacional. Percebemos que viver uma experiência com essas características é transformador. Contudo, não podemos 
deixar de mencionar o grande esforço necessário de cada um que decide se entregar para essa forma de relação. Identificamos que, em alguns trechos das versões de sentido já apresentadas, há menções às dificuldades desse processo. Percebe-se o desconforto inicial de romper as compreensões distorcidas da realidade, ou de perceber aspectos de si que podem ser desagradáveis. E além disso, o cansaço de manter a atenção constantemente na sua experiência. É, de fato, um movimento diferente do que se costuma fazer socialmente.

Estar em relações autênticas envolve o desenvolvimento de uma postura autêntica consigo mesmo também. Passamos a ser totalmente responsáveis por nosso processo de crescimento, bem como pelo desempenho de nossas funções. Deixamos de buscar culpados para as falhas e passamos a buscar alternativas para solucioná-las quando identificamos qualquer falha cometida.

Mudar a forma de se relacionar na vida é uma tarefa intensa, exige uma mudança de postura em todas as relações, e muitas vezes, nos deparamos com entraves, e situações difíceis de superar. Aprender a nos destituir dos juízos de valor e interpretações é outra tarefa muito difícil, exige muito esforço, vivemos uma realidade onde é comum acreditarmos que temos as melhores respostas. Aprender a apresentar para o outro claramente o que sentimos, sem feri-lo, sem nos sentirmos ferindo, também é trabalhoso, exige um esforço integral de cada um que se aventura nesse processo de transformação. $\mathrm{O}$ que percebemos é que a maior dificuldade em escolher viver diariamente com um grupo de pessoas que tem esse jeito de viver, é que estamos escolhendo nos transformar como pessoas em todas as relações, em nossa forma de olhar para a vida, então a jornada de trabalho acaba no final do dia, mas ainda existirá trabalho a ser feito após o expediente.

Assim como há dificuldades pessoais, também há dificuldades no âmbito organizacional. Na relação com as demais organizações e com o mercado é constante a dificuldade das pessoas de compreenderem as escolhas e os procedimentos organizacionais. Se faz necessário posicionamentos firmes e assertivos. Além disso, o desenvolvimento da organização é percebido com estranheza e, muitas vezes recebido com a aspereza da competitividade da nossa realidade comercial atual.

Apesar das dificuldades em viver essa experiência, é inegável que o clima facilitador de crescimento pode ser percebido na própria organização, quando olhamos para ela enquanto um organismo complexo em desenvolvimento. A conquista de reconhecimento e de espaço no mercado estadual têm se desenvolvido na proporção do desenvolvimento do grupo. Em cinco anos, a organização duplicou sua capacidade de fornecimento de serviços, aproximando-se da realização do seu potencial e adaptando-se às características fluidas da realidade.

\section{Considerações finais}

Diante do que foi exposto ao longo do artigo, compreende-se que a vivência dos postulados da Abordagem Centrada na Pessoa em uma organização de trabalho na atualidade apresentou-se de forma produtiva. Percebeuse o quanto a abertura à experiência e a fluidez se tornaram pilares necessários para a consolidação de relações organizacionais propiciadoras de crescimento tanto individualmente, quanto para o grupo como um todo, resultando em um crescimento da organização.

O desenvolvimento no contexto organizacional atual aponta para a valorização do ser humano, de sua capacidade criativa, de adaptação, fluidez e transformação. E o que percebemos neste relato de experiência é que a proposta organizacional centrada no grupo, se mostrou compatível com esta realidade, promovendo o desenvolvimento humano e organizacional à partir de relações que tem como premissa básica a comunicação livre entre todos os integrantes do grupo. A proposta de Rogers de compreensão e promoção das relações humanas, mostra-se cada vez mais frutífera e integrada a realidade atual.

Quando pensamos em contraindicações ou dificuldades da implantação e manutenção de uma organização centrada no grupo, o que percebemos é a necessidade de um trabalho interno, de abertura experiencial. As dificuldades podem se apresentar quando, por engano, utiliza-se esta proposta de forma tecnicista ou como um protocolo a ser seguido.

Estas reflexões expandem a proposta teórica de Rogers, levando seu legado à compreensão do desenvolvimento organizacional organísmico. Percebe-se que há uma constante reflexão sobre as limitações e os potenciais da organização e uma consideração das relações entre organizações e características da realidade. Só a partir disso, cada avanço ou recuo na estrutura dos serviços prestados é reconsiderado.

Rogers ao apresentar sua compreensão sobre a fluidez de sua abordagem teórica, referindo-se a estrutura geral de suas teorias, afirma:

Esperamos, igualmente, que tenhamos conseguido demonstrar que se trata de um sistema de certo modo "fluido", que não cessa de se modificar e de se precisar. (...) Sem dúvida, se as ideias essenciais de nosso sistema quase não apresentam mudança, numerosas mudanças se observam na significação atribuída às noções de base e na organização da teoria. Acreditamos, aliás, que este processo de revisão terá processo no futuro (Rogers \& Kinget, 1959/1977, p. 225).

Viver essa proposta nas organizações leva a fluidez em vários níveis. Nos tornamos mais fluidos como pessoas em cada uma de nossas relações, nos tornamos um grupo mais fluido, facilitando a organização de nossa rotina 
de trabalho e tornamos a organização mais fluida, capaz de se adequar as necessidades do mercado de trabalho e continuar em crescimento.

Sem sombra de dúvida, esse jeito de ser exige a entrega de todos, mas como resultado, todos se alimentam da direção encontrada para o crescimento.

\section{Referências}

Amatuzzi, M. M. (1996). O uso da versão de sentido na formação e pesquisa em psicologia. In: R. M. L. L, Carvalho (Org.). Repensando a formação do psicólogo: da informação à descoberta. Coletâneas da ANPEPP (p.11-24). Campinas: Editora Alínea.

Branco, P. C. C. (2008). Organismo: Tendência Atualizante e Tendência Formativa no fluxo da vida. In: F. S. C., Junior \& A. F. Feitosa. Humanismo de funcionamento Pleno: Tendência Formativa na Abordagem Centrada na PessoaACP. Campinas: Ed. Alínea.

Giddens, A. (1991). As Consequências da Modernidade. São Paulo: Edunesp.

Greening, T. C. (1975). Psicologia Existencial Humanista. Rio de Janeiro: Zahar Editores.

Knapp, P. \& Beck, A. T. (2008) Fundamentos, modelos conceituais, aplicações e pesquisa da terapia cognitiva. Revista Brasileira de Psiquiatria, 30(Supl. II), 54-64.

Marchiori, M. (2009). A Relação Comunicação - Organização: Uma Reflexão sobre seus Processos e Práticas. Comunicarte (Campinas), 29(39), 25-42.

Matson, F. W. (1975). Teoria Humanista: A Terceira Revolução em Psicologia. In T. C. Greening. Psicologia Existencial Humanista (pp. 67-82). Rio de Janeiro: Zahar Editores.

Paludo, S. dos S. \& Koller, S. H. (2007). Psicologia Positiva: uma nova abordagem para antigas questões. Paidéia, 17 (36), 9-20.

Rogers, C. R. (1974). Grupos de encontro. Lisboa: Moraes Editores (Original publicado em 1970).

Rogers, C. R. (1983). Um jeito de ser. São Paulo: EPU (Original publicado em 1980).

Rogers, C. R. (1997). Tornar-se pessoa (5ª ed.). São Paulo: Martins Fontes (Original publicado em 1961).

Rogers, C. R. (2001). Sobre o poder pessoal. São Paulo: Martins Fontes (Original publicado em 1977).

Rogers, C. R. \& Kinget, G. M. (1977). Psicoterapia e Relações Humanas ( $2^{\mathrm{a}}$ ed.). vol. 1. Belo Horizonte, MG: Interlivros (Original publicado em 1959).

Simeão, M. de O. \& Sousa, A. F. (2009). Psicologia do Trabalho numa perspectiva organísmica: inovações na condução e na avaliação do assessment. In A. Bacellar (Coord.). A Psicologia Humanista na Prática: Reflexões sobre a prática da Abordagem Centrada na Pessoa (pp. 69-91). Palhoça, SC: Ed. Unisul.
Siqueira, E. S. \& Spers, V. R. E (2001). Os Desafios das Organizações no Contexto Pós-Moderno. Impulso, 29, 155-168.

Anita Bacellar - Psicóloga, Especialista em Psicologia Clínica com base na Abordagem Centrada na Pessoa e Mestre em Educação pela Universidade do Sul de Santa Catarina (Unisul); Fundadora e Responsável Técnica do Espaço Viver Psicologia. Coordenadora, professora e supervisora do curso de Especialização em Psicologia Clínica. Endereço Institucional: Espaço Viver Psicologia. Rua Felipe Schmidt, $\mathrm{n}^{\circ}$ 315, sala 702 (Ed. Alliança). CEP 80010-001, Centro, Florianópolis. E-mail:anitabacellar@yahoo.com.br

Joana Simielli Xavier Rocha - Psicóloga e Especialista em Psicologia Clínica na Abordagem Centrada na Pessoa. Coordenadora de Serviços no Espaço Viver Psicologia. Instituição: Espaço Viver Psicologia. E-mail: joanasimielli@yahoo.com.br

Maira de Souza Flôr - Psicóloga clínica com Formação em Psicoterapia na Abordagem Centrada na Pessoa. Coordenadora de Serviços no Espaço Viver Psicologia. Instituição: Espaço Viver Psicologia. E-mail:flormaira@yahoo.com.br

Recebido em 27.04.2013 Primeira Decisão Editorial em 22.08.2013 Aceito em 12.05.2014 